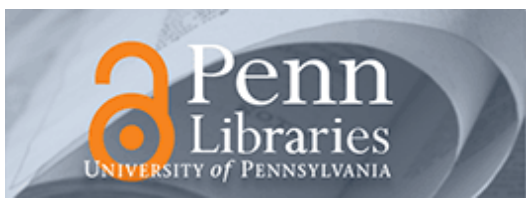

University of Pennsylvania ScholarlyCommons

Wharton Pension Research Council Working Papers

Wharton Pension Research Council

9-1-2013

\title{
Observations on Actuarial Assumptions and Models for Defined Benefit Pension Plans
}

Donald E. Fuerst

American Academy of Actuaries

Follow this and additional works at: https://repository.upenn.edu/prc_papers

Part of the Economics Commons

Fuerst, Donald E., "Observations on Actuarial Assumptions and Models for Defined Benefit Pension Plans" (2013). Wharton Pension Research Council Working Papers. 117.

https://repository.upenn.edu/prc_papers/117

This paper is posted at ScholarlyCommons. https://repository.upenn.edu/prc_papers/117

For more information, please contact repository@pobox.upenn.edu. 


\title{
Observations on Actuarial Assumptions and Models for Defined Benefit Pension Plans
}

\begin{abstract}
The goal of this paper is to review and comment on certain aspects of the Pension Insurance Modeling System (PIMS) and certain actuarial assumptions used by PIMS. The apparent stability of the deficit and funding ratio of the PBGC are partially dependent on a continued stream of premium payments from plan sponsors. However, derisking and other trends among retirement plans may change the pattern of premium income. Deterministic projections that supplement the stochastic simulations may enhance the understanding of the current deficit and the projected net claims over the next ten years.
\end{abstract}

\section{Disciplines}

Economics 


\title{
Observations on Actuarial Assumptions and Models for Defined Benefit Pension Plans
}

\author{
Donald E. Fuerst \\ September 2013
PRC WP2013-11
Pension Research Council Working Paper Pension Research Council
The Wharton School, University of Pennsylvania
3620 Locust Walk, 3000 SH-DH
Philadelphia, PA 19104-6302 \\ Tel.: 215.898.7620 Fax: 215.573.3418 \\ Email:prc@wharton.upenn.edu \\ http://www.pensionresearchcouncil.org
}

\begin{abstract}
The research reported herein was pursuant to a grant from the U.S. Social Security Administration (SSA) funded as part of the Retirement Research Consortium (RRC); the author also acknowledges support from The Pension Research Council at The Wharton School. All findings and conclusions expressed are solely those of the author and do not represent the views of the SSA or any agency of the federal government, the MRRC, the PRC, or The Wharton School at the University of Pennsylvania. All findings, interpretations, and conclusions of this paper represent the views of the authors and not those of the Wharton School or the Pension Research Council. (C2013 Pension Research Council of the Wharton School of the University of Pennsylvania. All rights reserved.
\end{abstract}




\title{
Observations on Actuarial Assumptions and Models for Defined Benefit Pension Plans
}

\begin{abstract}
$\underline{\text { Abstract }}$
The goal of this paper is to review and comment on certain aspects of the Pension Insurance Modeling System (PIMS) and certain actuarial assumptions used by PIMS. The apparent stability of the deficit and funding ratio of the PBGC are partially dependent on a continued stream of premium payments from plan sponsors. However, derisking and other trends among retirement plans may change the pattern of premium income. Deterministic projections that supplement the stochastic simulations may enhance the understanding of the current deficit and the projected net claims over the next ten years.
\end{abstract}

\section{Donald E. Fuerst}

Senior Pension Fellow

American Academy of Actuaries

1850 M. Street NW, Suite 300

Washington, DC 20036 


\title{
Observations on Actuarial Assumptions and Models for Defined Benefit Pension Plans
}

\author{
Donald E. Fuerst
}

The Pension Insurance Modeling System (PIMS) is a stochastic modeling system used by the Pension Benefit Guaranty Corporation (PBGC) and other parties to project certain risk exposures over periods of up to 20 years in the future. There are two versions of the system, SEPIMS for single-employer plans and ME-PIMS for multiemployer plans. The PBGC uses PIMS projection results principally in its exposure report to provide information about the range of possible future scenarios the single and multi-employer programs could face and the ability of the PBGC to meet its obligations. Supplemental uses include generating financial projections to estimate the effect of various legislative proposals. This paper examines certain aspects of these projections and suggests possible alternatives to enhance the understanding of these projections. Here we deal primarily with the single-employer system, so references to PIMS generally mean SE-PIMS unless the context clearly refers to the multiemployer program.

\section{The Nature of New Claims}

PBGC generally experiences a new claim due to a distress termination of a defined benefit (DB) pension plan. PIMS projects new annual claims for the next 20 years. A new claim is essentially the difference between the present value (at the time of the new claim) of the estimated future benefit payments to participants of the plan, less the market value of the plan assets that the PBGC takes over. The claim includes only benefits guaranteed by the PBGC, not any benefits in excess of the guarantee. The claim may be further reduced by any amount recovered by PBGC from bankruptcy proceedings. When PIMS projects a new claim, the interest 
rate used to determine the present value is based on the stochastic model, and it could be more or less than the rate used to evaluate previously existing claims at the financial statement date.

The present value of projected new claims reported in the most recent Exposure Report (PBGC 2012a: 8) is \$14 billion at the 15th percentile, \$34 billion at the mean, and \$55 billion at the 85th percentile. Each amount represents the present value of the difference between the gross claims (the present value of all future payments in each claim) and the present value of the assets taken over at the time of the claim.

\section{The PBGC Funded Ratio}

The \$29.1 billion deficit of the single-employer program on 9/30/2012 equates to a funded ratio of approximately 74 percent (assets of $\$ 82,973$ million divided by liabilities of $\$ 112,115$ million). The PIMS projections for the subsequent 10 years show a substantial range in the projected net position, from a $\$ 66$ billion deficit to a $\$ 1$ billion surplus. The median deficit is \$29.9 billion, a modest increase from the 2012 level. This median deficit equates to a funded ratio of approximately 77.6 percent based on mean liabilities (median liability was not disclosed in the exposure report, but would be somewhat less, producing a slightly higher funded ratio).

A preliminary look at these median projections might cause one to conclude that the PBGC financial situation is relatively stable. The deficit is projected to increase less than $\$ 1$ billion and the funded ratio increases by more than 3 percent. But the wide range of potential results serves as an immediate caution to such a conclusion, but there may also be other reasons to view this apparent stability skeptically. To understand one such reason, it is helpful to look at deterministic cash flow models of the PBGC’s financial position. 


\section{Future Cash Flow Projections}

The PBGC Annual Report (PBGC 2012b) and the Exposure Report (PBGC 2012a) describe the agency's current and projected financial status, but these could be expanded to provide additional useful information. Both reports provide the present value of future benefits, without showing the cash flows used to make this calculation. The projected cash flows by calendar year, without any interest discounting, could provide further useful insight into the financial obligations.

The Exposure Report indicates that, in the 5,000 scenarios simulated in SE-PIMS, none produced an exhaustion of funds during the 10-year projection horizon. Perhaps this is reassuring, but it does not prove that serious problems do not exist beyond the 10-year projection.

The 2012 deficit of $\$ 29.1$ billion implies a scenario where the single-employer program would exhaust its funds if the future is as anticipated by all assumptions, and no additional premium revenue were received. While this is a hypothetical scenario, it could be the first step in a series of useful projections. The existing assets would be augmented by investment income at the rate of 3.28 percent per year and reduced by the benefit payments for all obligations currently recognized by the PBGC. Under these assumptions, funds would be exhausted at a future date before all obligations had been met. This date could be 10, 20, 30, or more years in the future. Based on current benefit payments of $\$ 5.3$ billion per year, the exhaustion date would likely be more than 20 years in the future, but benefit payments will probably increase in future years, causing the potential exhaustion date to arrive sooner than projected.

The next useful step would be to combine this deterministic projection of cashflows with the PIMS projection of future investment income for existing assets. PIMS models future 
investment income based on the asset allocation of the current portfolio (approximately 70 percent fixed income and 30 percent equity). The projected income from the current investment portfolios at the 15th percentile, median, and 85th percentile could be substituted for the deterministic income projection at 3.28 percent. The median and 85th percentile projections would likely show an exhaustion date later than the 3.28 percent deterministic projection. The 15th percentile of investment income might shorten or extend the exhaustion date depending on the level of income. This comparison to the deterministic projection at 3.28 percent would provide a useful measurement of the expected gain resulting from the investment of part of the portfolio in equities as well as a measure of the additional risk resulting from this investment.

These measures of the cashflow projections provide additional information about the current status of the PBGC based on existing claims. These projections exclude additional assets the PBGC acquires in future years due to new distress terminations and additional premium income.

The deficit and funded ratio after 10 years under these projections could be compared to the deficit and funded ratio projection of the Exposure Report. This comparison would show the effect of future underwriting experience on the deficit over the projection period.

These additional projections would supply additional information concerning the effects of future premium collection and underwriting experience.

\section{Perverse Effect of New Claims}

At the median, PIMS projects underwriting losses in all future years. Despite this poor performance, the funded ratio improves over the 10-year projection period, and no projections indicate that the PBGC will run out of funds within 10 years. Why this apparent anomaly? As 
new claims occur, PBGC takes over both assets and liabilities of the terminated plans. The liabilities are greater, but the maturity of the plan and the duration of the new liabilities may be much different than PBGC's existing obligations. As new claims are added, if the duration of liabilities is longer than the duration of previous claims, the year in which assets will be exhausted can be extended. If the funded ratio of terminated plans (always less than 100 percent) is higher than the PBGC funded ratio before the new claim, the deficit will increase, but the funded ratio may improve marginally.

These apparent beneficial aspects of new claims are deceptive. Continued improvement depends on a continuing flow of these net claims. This might be possible in a robust and growing environment for pension plans, but in a world in which relatively few new plans are established and in which total coverage of plan participants is declining (PBGC 2010), a more difficult future may lie ahead. As the system gradually contracts, new claims will not extend the exhaustion of funds and may not affect the funded ratio, but instead will add to the total deficit.

\section{Assumptions Regarding Future Premiums}

PBGC currently projects future premium receipts assuming that only financially distressed companies will terminate their plans. Furthermore, there is no explicit assumption about changes in the size of existing plans. Yet in practice, many plans are shrinking, due to policies known as “derisking.” A sponsor implementing a derisking policy may offer plan participants the opportunity to receive a lump sum payment in lieu of all future pension payments. Another derisking policy involves purchasing an annuity from an insurance company which will then provide all future benefits due. After either of these financial transactions, the plan has liabilities and assets, fewer plan participants, but often no less unfunded liability. That 
is, the decrease in assets and liabilities is generally about equal, so the risk exposure of the PBGC is not significantly affected. However, PBGC premium income is dependent on the number of plan participants (fixed premiums are $\$ 42$ per participant in 2013, \$49 per participant in 2014, and indexed to inflation thereafter). In 2012, multiple large pension plans offered lump sum distributions to thousands of participants or purchased annuities for retirees ${ }^{1}$.

The Pension Protection Act (PPA) changes adopted in 2006 regarding lump sum distributions became fully effective in 2012. These changes make lump sum distributions less expensive for plans than prior to 2012. Previous requirements based the interest rate for the lump sum calculation on 30-year Treasury rates, but now the interest rate is based on corporate bond rates. The higher rate for corporate bonds results in lower lump sum calculations, so the lump sum distribution is less expensive to the plan sponsor. The lower amount should make lump sums relatively less attractive to participants, but they have not seemed to significantly reduce the number of participants taking lump sums so far.

An increasing number of plans offer lump sum distributions as a regular option for all participants at retirement or termination of employment (Aon Hewitt 2013). Cash balance plans are an example of this type design.

Service providers to frozen defined benefit (DB) plans often advise designing “glidepath” strategies. A glidepath strategy usually involves increasing the funded ratio of the plan and gradually derisking the plan investments as the funded ratio improves. The ultimate goal is usually to terminate the plan using a standard termination procedure when the funded ratio exceeds 100 percent. After a standard termination, the PBGC no longer has risk exposure, but it also lacks the premium income associated with the plan.

\footnotetext{
${ }^{1}$ General Motors, Ford and Verizon initiated substantial pension settlements in 2012.
} 
From 1991 to 2011, annual annuity purchases never exceeded \$5 billion. Now, some observers project that the annuity purchase market for qualified plans over the next five years may range from $\$ 35$ billion to $\$ 100$ billion (Mercer 2013). This could significantly change PBGC premium collections.

The increasing trend of lump sum distributions as regular options in some plans, the trend to offer lump sums to some inactive participants, the increasing tendency of plans to purchase annuities, and the acknowledged glidepath strategies of some plans sponsors, all suggest that the PBGC should examine the impact of assuming declining numbers of participants in covered plans and less premium income in future years.

\section{Importance of the Premium Income Assumption}

The current PIMS projections do not anticipate a decline in plan coverage, and which may make it difficult to identify an impending risk to the PBGC. The current projections, at the median, show little growth in the agency's deficit and modest improvement in funded ratios over 10 years. This demonstrates that, in a stable pension system, one in which there continues to be many plan sponsors and in which overall participation remains stable, it is possible to continue a pension insurance program without ever funding the deficit. As long as premium income and investment income are adequate, benefit payments can be made to all beneficiaries for many years, perhaps indefinitely, without full funding of the deficit. Sufficient premium income can continually defer the date at which funds might be exhausted.

The situation changes dramatically if participation and premium income begins to decline. Reductions in participants due to lump sum distributions and annuity purchases reduce 
premium income. Standard terminations of glidepath plans eliminate all premium income for the plan, but do not reduce PBGC exposure since a fully funded plan poses little risk to the PBGC.

As participation declines while risk exposure remains at similar levels, premiums may need to be increased to sustain financial viability of the PBGC. But at some point increasing premiums can accelerate sponsor actions to further reduce participation in covered DB plans, thus producing little or no additional revenue.

A revised assumption about future premium growth combined with the cashflow projections suggested earlier would provide valuable insight into the effects of declining plan coverage.

\section{Contribution Assumptions}

The PIMS model assumes that companies make the minimum contribution required. Yet, PBGC notes and other studies (Society of Actuaries 2011) have confirmed, that many companies make plan contributions in excess of the minimum. PBGC acknowledges that this assumption may cause variable rate premium projections to be overstated. For variable rate premium projections only, an adjustment is made to plan assets based on recent historical variable rate premium experience to lessen or avoid this overstatement.

This limited adjustment could cause an overstatement of exposure in two ways. First, higher contributions that companies make reduce the agency's risk exposure. Not only is the variable rate premium reduced, but the actual risk exposure of the PBGC is also reduced. Second, basing the adjustment on the recent historical variable rate premium experience is unlikely to capture behavioral changes resulting from a doubling of the variable rate premium from 2013 to 2015. Plan sponsors will soon have twice the incentive to make additional 
contributions and that incentive will continue to increase as the variable rate premium has been indexed to inflation after 2014. To the extent that plan sponsors react to this new incentive to fund plans, the ultimate risk exposure of PBGC may be lowered.

Balancing this point however, the PBGC notes that the plans most likely to respond to these behavioral incentives are the plans with relatively healthy sponsors who are less likely to fall into bankruptcy and distress termination. Those sponsors in less favorable financial circumstances seem slower to respond to incentives to fund more. If this trend dominates, the more dangerous exposure of the less healthy sponsors would not be reduced.

\section{Actuarial Gain/Loss Analysis}

An actuarial valuation involves many estimates about future experience. As actual experience emerges over time, the annual actuarial valuation measures the estimated experience against the actual and adjusts future estimates to reflect what has been learned about actual experience. The Annual Report of the PBGC includes a Reconciliation of the Present Value of Future Benefits from the previous year to the current financial statement date. This reconciliation includes certain actuarial adjustments.

The Exposure Report could usefully add comparisons of past projections to emerging experience, to soon provide better information on the sensitivity of these assumptions. For example, the 2012 Annual Report indicates that total premium income increased substantially from $\$ 2.08$ billion to $\$ 2.62$ billion. All of this increase was attributable to an increase in variable rate premiums ( $\$ 0.93$ billion to $\$ 1.49$ billion). On the other hand, the flat rate premium for single-employer plans had a small decrease, indicating fewer overall participants in the insurance program. If sponsors significantly increase contributions to reduce variable premiums, overall 
premium income might fall. Much of the increase in variable premiums may be the result of lower interest rates and thus higher liabilities. Rising interest rates could significantly affect this variable premium income. Further, since many single-employer pension plans have significant equity exposure in their asset portfolios, a rise in equity prices could also lower future premium income.

Projected benefit payments compared to actual payments might give insights into the appropriateness of several assumptions, particularly mortality and expected retirement age. Projected benefit payments could be compared to actual payments in a manner that splits existing claims at the previous valuation and new claims since the previous valuation. Comparisons might be based on three- or five-year periods rather than annual to provide greater statistical relevance.

Another interesting assumption that would benefit from comparison to actual experience is the assumption that plans involved in a bankruptcy will only result in a claim to the PBGC if the funded ratio of the plan at bankruptcy is less than 80 percent. Further information concerning this 80 percent assumption might also provide a better understanding of the projections. In particular, is this assumption consistent with recent experience? Are plan sponsors that are involved in bankruptcy able to maintain or fund up a plan that is 80 percent or greater? What is the dollar weighted funded ratio of distress termination plans in recent years?

\section{Simplifications}

SE-PIMS uses the RP-2000 mortality table with projections for determining a plan's mortality experience during the projections and the amount of underfunding at termination (PBGC 2012a: 18). After termination a greatly simplified assumption is used with one composite table using only male mortality experience (PBGC 2012c). Several other simplifying 
assumptions are used - all plans have uniform asset allocation, only single-life annuities are valued, and a single effective interest rate used instead of segment curves or the full yield curve. These simplifications probably have little significance when compared to the much greater variability of interest rates, investment returns and bankruptcy rates. Still, it is curious why a system as complex as PIMS uses only male mortality experience and only single life annuities.

\section{Alternative Plan Types}

PIMS was primarily designed to model primarily final average pay and flat dollar per year of service pension plans. Other plans designs are handled by simplifications or scaling factors. But existing DB plans evolve, these simplifications may become less appropriate and in need of change.

For instance, career pay plans have been one way in which plan sponsors have moved to limit risk in their DB plans. By basing benefits on career average pay rather than pay in the last few years of employment, the benefit liability is less leveraged to pay increases and generally grows more slowly.

Cash balance plans are one of the few types of DB plans that are frequently being adopted as new plans. A cash balance plan has a much flatter growth curve than a traditional final pay plan or even a career pay plan. Normal costs and liabilities grow at different rates than traditional plans, and so the model will require different projections as inputs, to reasonably project future growth and exposure.

Cash balance plans, like other account-based plans, often offer a lump sum benefit at retirement. And traditional DB plans are now offering lump sum distributions as well. To the extent that PBGC takes over plans offering lump sum distributions, the participants remaining 
are a select group that elected annuities rather than lump sums. If they experience lower mortality and greater longevity, this can pose a larger obligation on the PBGC. This antiselection effect could gradually make the mortality table used by PBGC inadequate for the actual experience of more select groups.

\section{Conclusions}

PIMS provides modeling and simulations of multiple highly uncertain events and outcomes. Many of the actuarial assumptions used in the PIMS model are simplified to reduce complexity and computation time. Some of these assumptions might be considered overly simplistic in a valuation of a typical pension plan (e.g. one composite mortality table, all male, all single life annuities), but in the context of simulations that must model the frequency of uncommon events such as bankruptcy, the margin of error produced by the simplification is not likely to be significant.

The usefulness of PIMS output and analysis could be enhanced by incorporating some deterministic projections. Cash flow projections that provide the ultimate year in which PBGC assets would be exhausted under various assumptions might prove especially useful. Understanding the current deficit would be enhanced by showing how long the funds on hand can cover payments to current retirees. Incremental additions to this projection, adding the likely income from actual portfolios, would add to the understanding of the nature of the assets and how risky investments add to uncertainty and potential returns.

The apparent stability of the deficit and funded ratio of the PBGC depend on a continued stream of premium payments from DB plans. But the increasing trend of derisking pension plans 
through lump sum distributions, annuity purchases, and investment strategies designed to lead to standard termination may produce decreasing premium income in future years. 


\section{References}

Aon Hewitt (2013). "Press Release: Survey Reveals More Employers Plan to Offer Lump-Sum Pension Payouts in 2013,” Lincolnshire, IL: February 13.

Mercer (2013). “Pension Risk Transfers Revisited,” Retirement Perspective: March 26. Pension Benefit Guaranty Corporation (PBGC) (2010) PBGC Pension Insurance Data Book 2010, Tables S-31 and S-33. Washington, DC: PBGC.

Pension Benefit Guaranty Corporation (PBGC) (2012a). FY 2012 PBGC Exposure Report. Washington, DC: PBGC.

Pension Benefit Guaranty Corporation (PBGC) (2012b). Excellence in Customer Service, Pension Benefit Guaranty Corporation Annual Report 2012. Washington, DC: PBGC.

Pension Benefit Guaranty Corporation (PBGC) (2012c). PIMS User Guide. Washington, DC: PBGC.

Society of Actuaries (2011). “The Rising Tide of Pension Contributions Post-2008: How Much and When?” Society of Actuaries Research Project. Schaumburg, IL: Society of Actuaries. 